\title{
Imagens da aposentadoria no discurso de pré-aposentados: subsídios para a orientação profissional
}

\author{
Gabrielle Ana Selig ${ }^{1}$ e Luciana Albanese Valore ${ }^{2}$ \\ Departamento de Psicologia da Universidade Federal do Paraná
}

\begin{abstract}
O estudo investiga imagens e expectativas concernentes à aposentadoria no discurso de trabalhadores de classe média em vias de se aposentarem, com o objetivo de identificar aspectos a serem abordados em programas de orientação profissional junto a essa população. Adotou-se uma metodologia qualitativa, referenciada na análise do discurso, e o instrumento utilizado consistiu em uma entrevista semiestruturada elaborada especialmente para a pesquisa. As principais recorrências encontradas foram: a relação de continuidade entre a aposentadoria e a inserção no sistema produtivo; a vinculação da identidade ao exercício de uma ocupação; o trabalho como principal organizador do tempo; a preocupação referente à condição econômica futura. Considerando-se o aumento da longevidade, a necessidade frequente de continuidade da vida laboral para a sobrevivência financeira e o reconhecimento social, conclui-se que a orientação profissional antes da aposentadoria ganha relevância, principalmente, no que diz respeito à construção de novas escolhas e projetos de vida, ao redimensionamento das imagens vinculadas à condição de aposentado e à reflexão sobre a relação identidade-trabalho.
\end{abstract}

Palavras-chave: Aposentadoria, Orientação profissional, Projeto de vida, Trabalho e identidade, Discurso.

Images of retirement in the discourse of workers about to retire: some aids for vocational guidance

This study investigates images and expectations in the discourse of middle class workers about to retire concerning their future. It intends to identify some points to be considered in retirement vocational guidance programs. A qualitative methodology was used based on the discourse analysis, and the strategy consisted on semi-structured interviews specially developed for this research. The main recurrences had been: the continuous relation between retirement and work; the identity bound to labor; the work as a main time organizer and concerns about further economical conditions. Considering the increase time life expectation, the need of a continuous working life in order to maintain a financial independence and social recognition, it is concluded that vocational guidance before retirement is important, mainly, in respect to constructing future choices and life projects, and shaping images about the retired condition, attending the relation between identity and work.

Keywords: Retirement, Vocational guidance, Life project, Work and identity, Discourse.

\section{Introdução}

$\mathrm{O}$ incremento na expectativa de vida, observado no contexto mundial, faz-se presente também na realidade brasileira. Estima-se que, em 2025, o Brasil ocupará a sexta posição em termos de envelhecimento populacional, com 31 milhões de pessoas com 60 anos ou mais (França \& Stepansky, 2005). Tal fato tem implicações relevantes para as novas formas de organização social e torna inevitáveis algumas questões: o que fazer com este tempo "a mais" de vida? Uma vez aposentado, dever-se-ia continuar com o mesmo ritmo de trabalho ou seria o ócio o melhor encaminhamento? Seria a aposentadoria o momento de realizar os planos não concretizados, como uma nova carreira? Como poderia se dar essa reorganização do tempo livre? Haveria um modo de se preparar para essa mudança?

1 Psicóloga e Bacharel em Direito pela Universidade Federal do Paraná. Mestranda em Psicologia pela mesma instituição.

2 Professora do Departamento de Psicologia da Universidade Federal do Paraná. Doutora em Psicologia Escolar e do Desenvolvimento Humano pelo Instituto de Psicologia da Universidade de São Paulo. 
Tendo em vista esses questionamentos, desenvolveu-se o presente estudo com o objetivo de investigar as imagens, expectativas e preocupações concernentes à aposentadoria, no discurso de pessoas em vias de se aposentar, a fim de delinear possíveis aspectos a serem considerados em um programa de orientação profissional direcionado à preparação para a aposentadoria.

Dado o discurso social de uma cultura de maior apreço aos valores associados ao juvenil (Calligaris, 2000), em que a imagem de aposentado geralmente encontra-se naturalizada na imagem de alguém "inútil" e "improdutivo" (García, Guerra \& Ardila, 2007; Medrado, 1994; Santos, 1990; Oliveira \& Santos, 2002; Veloz, Nascimento-Schulzel \& Camargo, 1999), supôs-se que o discurso das pessoas pesquisadas reproduziria tal imagem, evidenciando uma dificuldade em conceber a aposentadoria como oportunidade, tanto de repensar as escolhas feitas, como de fazer novas escolhas (quer no âmbito profissional, quer no âmbito pessoal). Talvez, para fugir do estigma da inatividade e manterem-se ocupados e produtivos (Haddad, 1986), alguns aposentados acabem simplesmente preenchendo o vazio deixado pelo não-trabalho, continuando a fazer as mesmas coisas (às vezes até o mesmo trabalho) sem considerar a possibilidade de novas escolhas, inclusive a do não trabalho. É como se "o gosto pela agitação, pelo movimento, pelo contato social constante fosse o melhor jeito de viver, significando que não viver assim não pode ser uma escolha, uma preferência, mas resultado de uma 'anomalia' existencial ou ... velhice" (Stelmachuk, 2005, p. 13).

Em que pese a limitação da amostra utilizada na pesquisa que fundamenta este artigo, espera-se contribuir, através dos elementos presentes nos discursos investigados, para a reflexão sobre os eventuais benefícios e os possíveis direcionamentos para o trabalho de orientação para a aposentadoria. Este, na medida em que visa à promoção da saúde e à instrumentalização do indivíduo para que organize ações de acordo com suas possibilidades/necessidades, pode se inserir no campo da Orientação Profissional (Goulart Junior, Ferreira \& Garbulho, 2005; Rodrigues, Ayabe, Lunardelli \& Canêo Silva, 2005).

Soares (2002), corroborando a afirmação acima, entende que a Orientação Profissional $(\mathrm{OP})$ deve ser vista de maneira abrangente, ou seja, englobando toda a atuação que tenha por objetivo analisar a relação indivíduo versus trabalho, seja no momento da escolha por uma atividade profissional, no planejamento de carreira ou no término da relação do indivíduo com o trabalho. A OP trabalha com o tripé: conhecimento de si, conhecimento do mundo e projeto de futuro (Soares, Costa, Rosa \& Oliveira, 2007). No caso da aposentadoria, esse projeto pode incluir ou não a busca por uma nova carreira. Portanto, embora este tema não seja novo na literatura (Amarilho \& Carlos, 2005; D'Andrea, 2000; França, 2002; Romanini, Xavier \& Kovaleski, 2004; Sánchez, 2000; Santos, 1990; Stelmachuk, 2005; Veloz et al., 1999; Zanelli \& Silva, 1996) entende-se que a discussão aqui feita poderá trazer contribuições para o campo da $\mathrm{OP}$, estendendo-lhe os horizontes para além da tradicional atuação com adolescentes.

\section{Trabalho: organizador da vida humana e da identidade}

Ao longo da história da civilização, as imagens vinculadas à ideia de trabalho nem sempre foram as mesmas (Chaui, 2000). Assim, se em seus primórdios, sugeriam algo próximo a um verdadeiro horror (exceção feita às ditas classes inferiores - pobres livres, escravos e prisioneiros de guerra - às quais não restava outra saída senão a de aceitá-lo como uma pena ou uma temível desonra), com o passar dos séculos, em função da reorganização social advinda da instituição do capitalismo e dos preceitos da reforma protestante, torna-se sinônimo de virtude, de dignificação da pessoa humana. Consequentemente, o não trabalhar passa a ser visto de forma pejorativa, incitando a exclusão e a marginalização social. Nas legislações iniciais do 
capitalismo, por exemplo, a mendicância e a preguiça caracterizam-se como crimes sujeitos à pena de prisão e, em certas hipóteses, até de morte.

Tal cenário não deixa de lembrar o atual. Afinal, o capitalismo faz crer que todos têm o dever moral e social de possuir um trabalho, instituindo na condição de não trabalho (como o desemprego ou a aposentadoria) atributos como culpa e vergonha (Chaui, 2000). Como corolário, observa-se o trabalho ocupando um lugar central na vida das pessoas - pensadas sempre, não importa a idade, como potenciais produtores (Santos, 1990; Veloz et al., 1999). Prova disso é a constatação de que o preparo para o exercício de uma profissão e para as demandas do mercado de trabalho vem se constituindo como finalidade das práticas educativas, cada vez mais cedo. Nessa perspectiva, o trabalho é visto como uma consequência natural e inevitável da vida (Santos, 1990). Talvez por isso a identidade profissional venha assumindo, de modo significativo, o cerne do processo identitário (D'Andrea, 2000; Mourão \& Andrade, 2001).

Para Bohoslavsky (2003), estudioso da problemática vocacional, a identidade ocupacional seria um dos aspectos da identidade pessoal. Tanto uma como outra, longe de serem dadas de saída, seriam construídas ao longo da vida. Para Dubar (2005), a identidade é um ato de pertencimento, pois, se se é determinada coisa, pertence-se a determinado grupo, categoria, classe social. Além disso, há que se considerar duas dimensões inseparáveis: a identidade para si (como eu me defino) e a identidade para o outro (como os outros me veem). Para o autor, "a identidade para si é correlata ao outro e a seu reconhecimento: nunca sei quem sou a não ser no olhar do outro" (2005, p. 135).

Considerando-se, na sociedade contemporânea, a crescente vinculação entre a identidade ocupacional e a identidade pessoal (França \& Stepansky, 2005; Santos, 1990; Siqueira et al., 2002, entre outros) pode-se imaginar que, ao romper com o mundo produtivo, o indivíduo possa vir a experienciar uma crise de identidade provocando sentimentos de inutilidade, vazio e baixa autoestima (Leal, 1991; Veloz et al., 1999). Nesse sentido, caberia perguntar: como superar os sentimentos de solidão e de não pertencimento? Como relativizar a crítica social introjetada de que o não trabalho é algo inadequado? Afinal, com a saída do mercado de trabalho, o indivíduo perderia o seu "valor mercantil", expressão de Caloni (1979, citado por Santos, 1990). Em função disso, não é de se estranhar a tendência, observada na atualidade, de prolongar a vida "produtiva" ao máximo, aumentando-se a idade para aposentadoria compulsória, dando-se incentivos - abonos de permanência - para aqueles que podem se aposentar, mas que optam por continuar no mesmo trabalho. Mas... que efeitos tais medidas produziriam na vida e nos modos de subjetivação das pessoas que se aposentam ou que pensam em fazê-lo?

Para alguns estudiosos do tema, a aposentadoria representa uma ruptura com o mundo produtivo do trabalho e com um ritmo de vida, mantido por trinta ou mais anos. Depoimentos de pessoas que se retiram de suas ocupações mostram como a experiência pode ser traumática, exigindo um difícil reajustamento (D'Andrea, 2000). Em uma sociedade na qual o trabalho e a produção são tidos como valores fundamentais (Lima, 1986, citado por Mourão \& Andrade, 2001), a aposentadoria é frequentemente sentida como a perda do próprio significado da vida (Santos, 1990), como perda de um ponto de referência na sua organização (Romanini et al., 2004). Isso porque o trabalho determina horários, atividades, relacionamentos, status e reconhecimento social, padrão de vida, relações com o tempo livre... Não por acaso, a aposentadoria - geralmente tão ansiada durante a vida laboral - ao ser concretizada, acena com tantas perdas. Em especial, a de um papel que, por muito tempo, fez parte da imagem e da definição de si mesmo.

O senso comum relaciona a aposentadoria ao ócio, à inutilidade, ao não fazer nada, o que leva muitas pessoas a não aceitarem a aposentadoria e a viverem-na com conflitos e ansiedade, sobretudo para aqueles que priorizaram a profissão em detrimento da vida pessoal e 
social. Para D'Andrea (2000), "ao se aposentar o indivíduo tem de abandonar seu grupo de iguais e essa separação é frequentemente a maior responsável pelos sentimentos de autodepreciação e de perda de amor" (p. 148).

Pesquisas feitas com trabalhadores americanos mostram que $85 \%$ dos participantes desejavam continuar trabalhando após a aposentadoria. Já, em um universo de aposentados, $62 \%$ permaneciam trabalhando porque gostavam, $26 \%$ porque precisavam do dinheiro e apenas $12 \%$ optaram por não continuar trabalhando para aproveitarem mais a família, amigos e viagens (Romanini et al., 2004). Outras pesquisas demonstram que, quanto maior o envolvimento e satisfação com o trabalho, mais difícil torna-se o desligamento (França, 2002; Zanelli \& Silva, 1996).

Esta parece ser a contradição da pós-modernidade: enquanto as novas tecnologias podem facilitar o trabalho e proporcionar mais tempo livre para o desenvolvimento de outros interesses, as pessoas prosseguem relacionando-se com o trabalho exatamente como há cem anos (De Masi, 2000, citado por França, 2002). Evidentemente, não se trata de negar a importância do trabalho para a configuração da subjetividade, em especial quando se refere a uma atividade que agrega satisfação e realização pessoal. Tampouco trata-se de conceber o exercício de uma ocupação, na aposentadoria, como algo necessariamente nocivo à saúde mental, sobretudo pela possibilidade de troca e de experiências alteritárias aí propiciadas, as quais, como já dito, possibilitam o reconhecimento de si pelo olhar do outro (Dubar, 2005). Entretanto, pode ser produtivo questionar a restrição dos espaços de convívio e do sentimento de pertencimento social ao contexto das relações de trabalho, como se não houvesse qualquer outra alternativa. Dito de outro modo, parece ser importante indagar sobre a possibilidade de, na atualidade, "ser alguém na vida" fora do cenário profissional.

Por fim, nunca é demais lembrar que a perda do papel profissional pode ser vivida diferentemente segundo o sentido e a importância que o trabalho assume na construção da identidade pessoal, pois nem todos os indivíduos investem igualmente na atividade profissional. Enquanto, para alguns, o trabalho é a atividade principal, senão única, de pertencimento, para outros, o trabalho é uma, dentre as demais, fontes de sentido da vida e de engajamento social. Talvez, nesse caso, a transição para a aposentadoria não acarretaria transformações profundas na identidade, pois teriam outros papéis de referência pessoal (Santos, 1990).

\section{Contribuições da orientação profissional para a preparação para a aposentadoria}

Os Programas de Preparação para a Aposentadoria (PPA) são geralmente desenvolvidos por equipes multidisciplinares. O presente artigo, dentro das limitações de seus objetivos, propõe-se a pensar na parcela desses programas que pode ser vinculada ao campo da $\mathrm{OP}$, tendo em vista, principalmente, os efeitos subjetivos produzidos por essa transição (Silva et al., 2005). A OP, nesse período de transição, pode ter um importante papel como psicoprofilaxia, na medida em que proporciona, aos futuros aposentados, condições de explorar suas expectativas, desejos e possibilidades (Soares et al., 2007), informando sobre as condições de vida pós-aposentadoria e ajudando-os a reconhecer que o processo de educação permanente pode contribuir para seu desenvolvimento psicossocial, estabelecendo novos desafios que valorizarão a própria existência (Felippe, Sandmann, Merthy, Fernandez \& Bulgacov, 1999; Siqueira et al., 2002). Essa orientação deve ter como objetivos facilitar o processo de transição, despertar novas áreas de interesse e prevenir conflitos emergentes, provocando uma mudança no comportamento desses indivíduos que, face à ruptura com o mundo do trabalho formal, buscam possibilidades de reconstrução de suas identidades (Zanelli \& Silva, 1996). 
Alguns autores criticam a orientação para aposentadoria afirmando que esse trabalho coloca o pré-aposentado na condição de sujeição, de alguém que precisa ser auxiliado por profissionais aptos a promoverem a sua reinserção social (Siqueira et al., 2002). No entanto, ao se pensar que a aposentadoria, em nossa sociedade, representa uma transição do ciclo de vida e que, como tal, pode ser vivenciada como um momento de crise e de sofrimento, tais atividades de orientação podem justificar-se, sem necessariamente incorrerem no risco de sujeição. Além disso, o aumento da expectativa de vida da população e a negligência usualmente presente na relação com aqueles que se aposentam e passam a ser vistos como inúteis para o sistema produtivo exigem um complexo reajustamento social (D'Andrea, 2000).

A aposentadoria em si não é um problema. Ela é um benefício conquistado historicamente pelos trabalhadores, podendo transformar-se em uma chance para a descoberta ou o retorno ao que se gosta, ou a um "fazer" mais fácil, menos sacrificado e mais agradável do que o anterior. Assim, o que entra em questão é a relação que o indivíduo estabeleceu - e que poderá vir a estabelecer - com o trabalho e com o não-trabalho; o modo, particular, com que irá lidar com o movimento de desestruturação e de reestruturação da identidade pessoal que esse período da vida comporta. Este será mais ou menos difícil dependendo de como o aposentado organizou sua vida, da importância que deu ao trabalho e dos vínculos sociais que construiu (Romanini et al., 2004; Zanelli \& Silva, 1996).

\section{Metodologia}

Participantes: 3 homens e 3 mulheres próximos à aposentadoria (menos de 5 anos). Desses, 4 são servidores públicos ( 2 da área de Educação e 2 do Poder Judiciário) e 2 são de uma instituição privada da área de Educação. Todos, sem exceção, exercem em seus locais de trabalho atividades administrativas. Os entrevistados do sexo masculino contavam, na data da entrevista, com 32, 33 e 40 anos de tempo de contribuição formal. As entrevistadas possuíam 27, 30 e 30. Suas idades variaram entre 50 e 59 anos. Quatro são casados e 2 divorciadas, todos com filhos. Com relação à escolaridade, 4 têm curso superior completo e 2 têm ensino médio completo. Todos pertencem à classe média, com renda igual ou superior a 5 salários mínimos.

O critério para a composição do grupo foi a seleção deliberada (Morse, 1994). Os primeiros entrevistados foram indicados por pessoas das relações das pesquisadoras, que sucessivamente indicaram outros. Procurou-se entrevistar pessoas de diferentes instituições, com diferentes tempos de contribuição, estado civil e experiências profissionais, visando à obtenção de discursos diferenciados. A heterogeneidade da amostra permite que se atribua um maior peso retórico às semelhanças discursivas, que se identificam à medida que se transcrevem e analisam-se as entrevistas (Llombart, 1995, citado por Nogueira, 2006)

Todos foram informados sobre os objetivos e os procedimentos éticos da pesquisa (sigilo em relação à identificação pessoal e do local de trabalho) tendo assinado um termo de consentimento livre e esclarecido autorizando a utilização dos dados para fins de divulgação científica.

Instrumento: Elaborou-se um roteiro de entrevista semiestruturada, especialmente construído para os propósitos do estudo e em consonância com o referencial de análise adotado. Para testar o instrumento, foram realizadas entrevistas piloto. Os temas abordados foram, entre outros, dados pessoais, imagens a respeito da aposentadoria, pretensão ou não de se aposentar quando legalmente apto; significado atribuído ao trabalho; atividades fora do trabalho; sonhos e receios para a aposentadoria; relação com a família. As entrevistas foram realizadas no local de trabalho dos participantes, tendo sido gravadas e posteriormente transcritas de modo a obter um registro fidedigno das falas. 
Procedimentos de análise: seguindo os procedimentos propostos pela análise institucional do discurso (Guirado, 2006; Guirado \& Lerner, 2007; Valore, 2005) cada entrevista foi analisada separadamente com o objetivo de evidenciar as repetições, rupturas no dizer, contradições, descontinuidades etc. Atentou-se, sobretudo, aos modos de dizer, aos verbos, sujeitos e adjetivos usados; à posição do sujeito do enunciado; aos múltiplos sentidos; às naturalizações instituídas. Na sequência, as entrevistas e suas análises foram confrontadas para recortar os principais eixos discursivos em torno dos quais os participantes organizaram suas falas. Em seguida, agruparam-se os extratos discursivos organizados em torno de cada um desses eixos, de maneira a evidenciar novas recorrências e nestas, o modo singular com que cada entrevistado enunciou sua fala. Por fim, tais análises e discursos foram relacionados à literatura pesquisada sobre o tema.

\section{Resultados e discussão}

O processo de análise dos depoimentos obtidos permitiu evidenciar um eixo comum em torno do qual os discursos se organizaram, a saber: o das relações (de continuidade ou de ruptura) entre o período laboral e a aposentadoria. Tais relações puderam ser delineadas, sobretudo, no modo como os entrevistados construíram suas imagens, sonhos, expectativas e receios, em relação à aposentadoria, em suas falas. Evidentemente, esse resultado relaciona-se aos objetivos da pesquisa, os quais nortearam a estruturação e o modo de formulação das questões abordadas nas entrevistas. Estas, seguindo as proposições da análise do discurso, não visavam comprovar qualquer hipótese: ainda que algumas suposições estivessem presentes, buscou-se, no geral, construir as perguntas da forma mais aberta possível, a fim de favorecer a fala dos entrevistados e não a confirmação ou negação da fala do entrevistador.

A discussão dos resultados buscou evidenciar as principais recorrências nos discursos e, ao mesmo tempo, algumas singularidades. Vários poderiam ter sido os extratos discursivos selecionados. No entanto, optou-se por eleger um recorte, o qual, no caso, focou a atenção nos extratos que melhor ilustravam os principais eixos discursivos em torno dos quais as falas se organizaram. Como já dito, o eixo comum consistiu nas relações entre o período laboral e a aposentadoria. Derivado deste, outros puderam ser identificados e serão também tratados na exposição e discussão a seguir. São eles: as relações (de continuidade ou de ruptura) entre a identidade pessoal e a identidade ocupacional; a organização do tempo pelo tempo de trabalho; o empobrecimento e a perda da dignidade na aposentadoria. Cabe observar que os nomes atribuídos aos participantes são fictícios, com vistas a preservar sua identidade.

\section{Aposentadoria: ruptura ou continuidade do período laboral?}

Lauro (50 anos, 33 de serviço) vê a aposentadoria como continuidade, pois esta equivale a trabalho. A ruptura se dá na condição em que ele se vê, executando um trabalho voluntário e não compulsório: “... eu esperava me aposentar logo e já começar com o trabalho voluntário". Esse continuar trabalhando, mesmo que sem remuneração, indica uma identificação entre identidade pessoal e profissional. Ou seja, um eu que existe através do fazer, um eu que precisa do trabalho para se definir e pertencer. Ao trabalhar, Lauro garante a continuidade de seu modo de ser "acelerado". O trabalho é matriz de identidade pessoal, do modo como ele se vê: uma pessoa que não pode parar: "É, fazendo trabalhos voluntários mesmo... Não ficar parado, né? Eu não consigo ficar parado. Meu ritmo é sempre acelerado, né?". 
Assim, para esse entrevistado, o ritmo do trabalho garante o ritmo do eu (que não para). Um eu que se afirma e se estima na relação com o outro, com a sociedade. Um eu que, através do trabalho, pode ver e ser visto:

Ah, bom, [o trabalho] é uma necessidade, né, e também uma autoafirmação, uma autoestima. Ele traz um desenvolvimento, uma aprendizagem, é, relacionamento, né, atualização da situação da sociedade, né, e tudo isso envolve... Uma pessoa que não está envolvida nesse ritmo de trabalho e atividade social, ele se retrai, ele não tem a mesma, ah, ele perde aquela visão, aquele contato das suas necessidades e das necessidades do meio.

Se não houver a manutenção do ritmo, a aposentadoria pode ser sentida como uma propensão à doença. Ou seja, para uma aposentadoria saudável não pode haver uma quebra do ritmo, há que se continuar com as atividades: “... a gente percebe a questão de doença, as pessoas que estão muito propensas à doença, elas estão muito, é, paralisadas né no seu ritmo. Então não tem expectativa nenhuma. Então elas estão mais suscetíveis, né?".

Mário (59 anos, 40 de serviço) inicialmente fala da aposentadoria como ruptura. Vê-a como descanso, descompromisso, como possibilidade de fazer coisas que não consegue fazer devido à sua rotina de trabalho:

Penso em duas coisas, primeiro realmente é descansar da correria, a gente na verdade sente uma pressão de compromisso que a gente tem hoje, de horário, de tudo, né, é o compromisso que a gente tem que cumprir... É esse descompromisso que facilita daí, não estar tanto preso a horário e ter tempo disponível para fazer bastante coisa que a gente não consegue fazer hoje...

No entanto, logo em seguida, traz a noção da aposentadoria como continuidade. Para ele, o aposentado deve ocupar-se em fazer alguma coisa, não ficar parado, estar sempre em atividade. Muito embora mencione diversas atividades que costuma fazer com frequência, percebe-se que, na verdade, estar em atividade representa, para ele, estar trabalhando, mesmo que seja algo voluntário:

E se ocupar realmente em fazer alguma coisa porque eu acho que o complicado é a pessoa
ficar tomando sol, o aposentado, porque aí complica (...) E talvez não ser aquele
aposentado mesmo de ficar em casa, estar sempre em contato com as coisas que a gente
gosta, inclusive os colegas, ex-colegas. O [nome do local de trabalho] até dá a chance para
isso, de trabalhar aqui como voluntário, isso dificilmente eu vou me afastar.

Esse conflito entre ser a aposentadoria uma ruptura ou uma continuidade talvez represente a contradição entre o desejo do descompromisso e o medo de perder-se, de não se reconhecer, de se sentir "inútil" ao deixar de realizar as atividades que fez rotineiramente nos últimos trinta anos:

Eu acho que o mais feliz da aposentadoria é você estar disponível para qualquer coisa, até para não fazer nada. Mas você estar realmente e se sentir motivado, eu acho que essa mentalidade tem que mudar também aqui no Brasil, aposentado não é um inválido, como existe ainda um pensamento acho que errado na sociedade, né? Aposentado não para, ele é uma pessoa ainda, ele deu sua contribuição e ainda tem muito pra dar.

Sidnei (53 anos, 32 de serviço) também vê a aposentadoria como continuidade, como algo que faz parte da vida das pessoas. Como os demais, percebe-se como uma pessoa que não pode parar, que precisa de outras atividades para "aguentar": "Não quero ficar parado, porque uma pessoa bem ativa não consegue só ficar em casa, não vai aguentar". E ficar inativo, seu principal medo, "leva você a se debilitar, ficar cansado, perder a vontade da vida". Além disso, a aposentadoria poderia, enfim, representar a oportunidade de uma realização pessoal -talvez 
postergada durante a vida laboral: "Eu entraria [com o pedido de aposentadoria] porque eu quero dar aula, né? O que eu gosto mesmo é lecionar. Isso que eu pretendo fazer depois de aposentado, o que eu gosto".

Larissa (50 anos de idade, 30 de serviço) entende a aposentadoria como ruptura, principalmente no que tange aos compromissos de horário, a ter mais liberdade para organizar seu tempo. No entanto, também se vê como uma pessoa que não pode parar, que precisa ter outra atividade (trabalho) para não "ficar nervosa", "atacada":

Quero me aposentar, ter um tempo inclusive para fazer academia, porque eu tenho problemas de circulação, trabalho muito tempo sentada, eu não ando. Tempo para poder caminhar, ir para academia, viajar. Mas também não quero parar. Quero fazer alguma outra coisa. Eu sou muito nervosa, muito atacada. Se eu ficar o tempo inteiro dentro de casa eu vou matar meia dúzia [risos].

Manter a atividade é sinônimo de manter-se viva, pois se a pessoa é sozinha e para de trabalhar pode "morrer logo". Morrer é não poder ver e não poder ser vista:

Medo [da aposentadoria], eu não! A minha irmã morre de medo... há dois anos poderia ter se aposentado... Ela é viúva, uma pessoa muito fechada... Diz que pelo menos ela vai ali no trabalho, ver gente. Ela tem medo de ficar em casa sozinha, de repente ela morre logo.

Ingrid (56 anos, 30 de serviço), por sua vez, tem dificuldade em imaginar-se aposentada. Parece que a aposentadoria representa uma ruptura insuportável de sua identidade e, portanto, vê como única possibilidade o continuar trabalhando: "Não penso em estar aposentada, só consigo imaginar eu continuando a trabalhar. Gosto daqui, do que faço". A aposentadoria é vista por ela como ameaça de falta de saúde:

Vou continuar trabalhando até que [nome do local de trabalho] me dispense, até que não me queiram mais. Gosto do que faço, me sinto bem. Continuo no trabalho enquanto tiver saúde. Não quero ficar jogada dentro de casa, sem nada para fazer, só pensando em besteira e comendo um monte, engordando.

A aposentadoria, vista como uma possibilidade de inatividade, é sentida por esses depoentes como possibilidade de doença e a responsabilidade pelo manter-se bem é atribuída à pessoa do aposentado, demonstrando um desconhecimento do contexto social que pode contribuir para o "deixar cair", como afirma Mário:

Olha, é preocupante [referindo-se a pessoas aposentadas]. Por isso eu conheço pessoas, a maioria não estão bem, estão até depressivas, pelo modo de vida que eles deixaram cair, não dão uma continuidade a atividades, ao que estavam ... não são tão diferentes aí fora.

Já para Gertrudes (50 anos, 27 de serviço), a aposentadoria é vista como ruptura em relação a um ambiente estressante e competitivo que a oprime. Representa, assim, "A coisa mais feliz que pode acontecer na minha vida. A maior tranquilidade na minha vida acho que vai ser, é fazer nada o dia inteiro, fazer coisas só pra mim".

Seu trabalho parece ser fonte de sofrimento e angústia, algo que é obrigada a fazer para sobreviver. Para ela, aposentar-se é recuperar um tempo perdido e o que de si mesma parece ter se perdido nesse tempo:

[Falando sobre o que diria a uma pessoa que está começando a trabalhar] Não trabalhe desesperadamente, muito mais do que aquelas suas horas, você não precisa mostrar isso para ninguém, para se garantir. Eu sempre fiz isso para garantir emprego, segurança [choro]. Dá uma tristeza, né? Para garantir o emprego você se humilha, mata um leão por 
dia, eu estou cansada disso, todo dia aquele terrorismo, agora sempre é a vez dos jovens [choro]. A gente sente isso, dá impressão que a gente não presta mais.

À exceção desta última entrevistada, os demais, confirmando o que diz a literatura, veem a aposentadoria como continuidade da vida laboral, pois, se assim não for, esse momento de mudança poderá trazer adoecimento, solidão, não pertencimento, morte. Ingrid traz, inclusive, a vontade de prolongar ao máximo sua vida "produtiva", para não perder seu "valor mercantil" e, consequentemente, seu valor enquanto pessoa.

Parece que todos os entrevistados priorizaram o trabalho em detrimento da vida pessoal e social, sendo que alguns - como Gertrudes, Mário e Sidnei - nitidamente deixaram a realização pessoal como um projeto a ser executado após a aposentadoria. No entanto, a realização pessoal consiste em continuar trabalhando:

A realização pessoal sempre fica como num esboço de projeto para ser executado após a aposentadoria, e quando essa chega os entrevistados, em sua maioria, se sentem surpresos e desencantados por não saberem gerenciar com prazer a existência sem uma ocupação profissional, mesmo quando essa atividade tinha sido executada com insatisfação (Bruns \& Abreu, 1997, p. 5).

Como pôde ser observado nos depoimentos apresentados, o trabalho é uma importante matriz da identidade pessoal, da construção da autoimagem. $O$ trabalho, fonte de estima e autovalorização, é também uma forma de estar inserido no meio, de pertencer (daí a aposentadoria ser imaginada como continuidade).

\section{As relações entre a identidade pessoal e a identidade ocupacional}

Conforme traz a literatura (França \& Stepansky, 2005; Santos, 1990; Siqueira et al., 2002; entre outros), o trabalho assume um papel predominante na construção da identidade pessoal, sendo a atividade principal, senão a única, de pertencimento. O não trabalho significa, para estes pré-aposentados, não-reconhecimento, não-pertencimento. Essas pessoas tenderam a direcionar suas vidas em torno da ação, do fazer e, ao se aposentar, poderão descobrir que todos seus interesses e relações estavam vinculados ao mundo do trabalho (França, 2002).

Para Mário, por exemplo, o trabalho parece estar tão intrinsecamente ligado a sua identidade pessoal que se refere ao não-trabalho como "lá fora", como algo que estivesse apartado, excluído, de dentro de si mesmo: "Você vai poder desenvolver, aproveitar toda tua experiência, todo o teu conhecimento na ativa pra uma atividade lá fora. Você também poder contribuir como cidadão com alguma atividade, de alguma forma lá fora".

Traz cristalizado o discurso capitalista através do medo de, como aposentado, ser considerado velho e inútil; ou seja, mantendo-se em atividade (mesmo que voluntária) torna-se mais uma vez trabalhador e, portanto, útil, produtivo e "experiente":

... Eu acho que é isso que eu te falei, é preciso se preocupar mais no nosso país com, uma coisa que tem tudo a ver com tudo, não considerar as pessoas velhas, mas sim experientes, né? Os aposentados não podem ter uma pecha assim de, um rótulo, assim (...) Eu acho um absurdo (...) que se proíba de se taxar as pessoas de incapazes e até pra preparar pra aposentadoria em fazer alguma coisa, em algo que eles possam ser aproveitados depois da aposentadoria pra produzir pro país e pra ele se ocupar também.

Tal lógica capitalista repete-se na fala de Sidnei de que a pessoa que para de trabalhar para produzir, portanto, deixa de ser útil: "o trabalho, como diz o pessoal, dignifica a pessoa. Eu acho que a pessoa que não trabalha não produz nada para si e não produz nada para o futuro de si próprio e dos filhos. Começar a trabalhar o quanto antes, não machuca ninguém, só faz bem". 
A preocupação em manter-se produtivo e, implicitamente, em ter reconhecido o seu valor como pessoa é recorrente nos discursos. O comentário de Mário chama atenção. Para ele: "Aposentado não para, ele é uma pessoa ainda, ele deu sua contribuição e ainda tem muito pra dar". Assim, o aposentado deve ocupar o tempo, inclusive, fazendo coisas que ninguém gosta de fazer: "... usar as pessoas de idade para uma série de coisas que ninguém quer fazer e que eles gostam dessas atividades".

Sendo o trabalho a atividade principal de pertencimento, a aposentadoria, para esses entrevistados, poderá ser vivida como crise (ou ser adiada ao máximo, como está fazendo Ingrid), pois o não-trabalho significaria não-reconhecimento, não-pertencimento, adoecimento. Parece que, ao direcionarem suas vidas em torno do fazer, acabaram deixando um pouco de lado o ser. No entanto, Mário dá sinais de estar se conscientizando desse fato ao relatar que uma das maiores descobertas que fez neste período de pré-aposentadoria é a de que dedicou muito tempo ao trabalho, vendo a necessidade de agora, com a proximidade da aposentadoria, conciliar a vida "lá fora" com a vida no trabalho. Assim, daria este conselho a quem está começando a trabalhar: "Principalmente conciliar, o que eu estou fazendo agora: conciliar minha vida lá fora com aqui, pra que não haja muita diferença, senão você entra num choque às vezes...”.

Ou seja, ver o trabalho como uma das possibilidades de construção do ser humano, que deve lhe permitir autonomia com relação a todas as atividades nas quais está imerso como condição do próprio existir (Bruns \& Abreu, 1997).

\section{A organização do tempo pelo tempo do trabalho}

Outra recorrência nos discursos é a questão do tempo. Como diz Mário: "se você bobear, chega seu tempo, passa seu tempo e você não vai fazer nada a tempo". Tal como os demais, este entrevistado fala do medo de não poder usufruir o tempo que "lhe resta", como se tivesse feito uma poupança de coisas para fazer após a vida laboral:

... [Tratando do que tem receio] só se surgisse alguma coisa de eu não poder fazer nada, tipo ficar doente, uma doença grave. Só isso... Só isso... Continuar minha vida como eu estou, com família, bem casado, bastante amigo, essas coisas, o medo é a gente ficar impossibilitado de usar este tempo, porque parado eu não vou ficar.

Gertrudes, igualmente, traz a ideia de que precisa aproveitar a vida antes de estar velha, como se tivesse postergado o "viver a vida" para depois da aposentadoria:

\footnotetext{
Nossa, faz horas que eu penso nisso [em estar aposentada]. Faz uns três anos que eu faço essa continha. O que me levou a pensar nisso foi o cansaço. O cansaço. E pensar que eu não quero parar de trabalhar para aproveitar minha vida. Eu quero aproveitar antes. Eu não quero estar velha. (...) O prazo é curto, dez anos para chegar aos sessenta. Tem que aproveitar muito mais antes. Não quero o período para aposentar velha, quero aproveitar antes.
}

O tempo parece objetivamente organizado pelo tempo de trabalho versus o tempo livre (de não-trabalho). $\mathrm{O}$ trabalho, confirmando o que diz a literatura, parece ser realmente $\mathrm{o}$ principal organizador do tempo - quando não o único, como nos casos de Ingrid e de Larissa, que mencionam o trabalho como a única atividade que fazem.

Cabe indagar, no entanto, por que, ao mesmo tempo em que anseiam por mais tempo livre, esses pré-aposentados - à exceção de Gertrudes - têm uma preocupação extrema em ocupar o tempo e, portanto, ficar sem tempo livre. A que essa liberdade de tempo remete? Qual o medo do tempo livre? Medo de deparar-se com a finitude da existência? Medo de deparar-se 
com as frustrações dos desejos não realizados? Deparar-se consigo mesmo? Será essa ocupação do tempo livre uma forma vazia de existência?

Para não sofrer a angústia, poderiam os "sem tempo" estar fugindo do que em si mesmos causa o temor (que poderia desvelar-se no tempo "para si"?), decaindo como podem no mundo das ocupações ou no impessoal (do tempo "em si")? (Grassi, 2007, p. 50).

Ou seja, será que estes pré-aposentados estão pensando em ocupar o tempo de forma vazia ou estão imaginando utilizar esse tempo para si mesmos, para sua expansão como seres humanos, para o enriquecimento pessoal? Afinal, como afirma Gertrudes, referindo-se às pessoas que conhecem e já se aposentaram: "Eles estão muito bem. Estão falando assim, que dá trabalho cuidar da gente também, cuidar de si, mas que é bom, é”.

Quando a aposentadoria chegar, será que o fato de a pessoa ter sido condicionada a realizar um trabalho rotineiro e alienante, sem limites a explorar, repetindo e reproduzindo sempre não a impossibilitará de visualizar um gerenciamento criativo de seu tempo livre? (Bruns \& Abreu, 1997). Afinal, como afirmou Mário:

... porque aqui nós estamos amarrados em um compromisso. Depois você vai ter que fazer teu tempo, teus horários. Aí complica um pouco. É mais difícil do que aqui. Aqui a chefe te dá uma ordem e você faz. Você sabe o que vai planejar pro teu trabalho. Está tudo escrito, previsto. Lá fora é você que vai organizar tudo isso. E isso eu já tive experiência, de ver, perceber que as pessoas se perdem.

\section{O empobrecimento e a perda da dignidade na aposentadoria}

Outra preocupação marcante nos discursos é a condição econômica: "continuar fazendo alguma coisa, viajar, que eu acho interessante a gente poder ter liberdade para viajar, que o dinheiro dê, né?" (Mário); "então a única preocupação que eu tenho assim é ficar livre das dívidas" (Lauro); "Falar para o jovem, como minha mãe falava: guarde dinheiro, se eu tivesse uma poupança eu poderia pedir já minha aposentadoria. $O$ dinheiro não deixa a pessoa presa no trabalho. Se eu tivesse a poupança..." (Gertrudes); "Acho importante você ter seu dinheiro, principalmente por causa da saúde. É duro depender do INSS. Pior ainda é depender da saúde pública quando precisamos de atendimento" (Ingrid).

Pesquisas, como a de França (2002), demonstram que mesmo sendo diversos os fatores que afetam o bem-estar na aposentadoria, o empobrecimento é a ideia mais comumente associada a essa fase de vida. Segundo Veras (1999, citado por França, 2002), "o idoso brasileiro tem, ao final de sua vida, uma situação financeira pior do que quando trabalhava, pois o valor de sua aposentadoria, na maioria das vezes, é inferior aos seus ganhos durante o período produtivo" (p. 21). Assim, para garantirem a própria sobrevivência, muitos aposentados são instados a continuar trabalhando. A perda do poder aquisitivo com a aposentadoria favoreceria a perda da autonomia e, consequentemente do sentimento de dignidade (França, 2002, p. 30). Afinal, em uma sociedade de consumo, o lazer está muito vinculado ao que se pode comprar:

Aposentadoria feliz? Uma coisa é certa: o dinheirinho certo. É uma coisa que você não precisa ir todo dia bater o ponto para ter certeza que vai ganhar seu dinheiro no final do mês. Isso é uma coisa muito feliz (Gertrudes). 


\section{Conclusões}

A análise dos discursos dos pré-aposentados corrobora a literatura: efetivamente, para eles, a aposentadoria é vista como continuidade do trabalho e do próprio eu (que se afirma e estima na relação com o outro). Ademais, essa continuidade garantiria a saúde, pois a inatividade, estereótipo da aposentadoria presente nesses discursos, é vista como possibilidade de doença. Imaginada como ruptura (em um trabalho considerado bom, como para Ingrid e Mário), gera medo e insegurança.

Por outro lado, a aposentadoria pode ser intensamente desejada, em uma visão igualmente estereotipada, como uma espécie de salvação. Tal é o caso, como se viu, de Gertrudes, em que o desligamento do trabalho parece representar a libertação de tudo o que a oprime. Em outras falas, igualmente, percebeu-se uma idealização desse momento como oportunidade de realizar tudo o que ficou para trás. E, se isso pode ser considerado positivo, na medida em que acena com a possibilidade de revisão das escolhas feitas, sugere, entretanto, a necessidade de investigar se tal anseio não estaria encobrindo a angústia derivada dos lutos inevitavelmente associados a esse momento de transição (como se não houvesse lutos a elaborar, possíveis crises e novas frustrações a enfrentar). Como hipótese, supõe-se que, em alguns casos, a idealização da aposentadoria como momento em que "enfim, vou ser feliz!" possa surgir como defesa para a crise de identidade que essa condição geralmente provoca.

Outras imagens, que corroboram a literatura consultada, referem-se às preocupações com a condição econômica. $O$ dinheiro é visto como algo essencial para se viver dignamente a aposentadoria (seja pela liberdade ou pelos cuidados com a saúde), uma preocupação bem justificada diante da realidade socioeconômica brasileira.

Por fim, nessas imagens, chama a atenção a relação estabelecida com o tempo livre. Simultaneamente desejado e temido, tal aspecto sugere a necessidade de outras pesquisas em que tal ambivalência possa ser investigada. Como afirma Stelmachuk (2005) "o lazer e o tempo livre não são valorizados nas sociedades que cultuam o trabalho como valor superior" (p. 16).

A suposição inicial deste estudo mostrou-se parcialmente verdadeira. $\mathrm{O}$ discurso dos pré-aposentados reflete a cristalização dos sentidos oriundos das formações discursivas de uma sociedade capitalista que supervaloriza o trabalho em detrimento do ser humano, que atribui ao aposentado o lugar de "não mercadoria", de inutilidade. No entanto, ainda que o temor de tornar-se improdutivo seja o norteador das imagens de futuro, ao contrário do que se supôs, a aposentadoria também pôde ser pensada como oportunidade de novas escolhas. Vide a possibilidade vislumbrada por Lauro e Mário de realizarem-se através de trabalhos voluntários, o projeto de Sidnei de lecionar (fazer o que realmente gosta), a vontade de Gertrudes de aprender a utilizar o tempo livre para si, a percepção de Mário de que é preciso conciliar o trabalho com outras formas de obtenção de reconhecimento, como a família.

Em relação ao segundo objetivo desta pesquisa - evidenciar os elementos a serem considerados em uma orientação para a aposentadoria, conclui-se que tal orientação só faz sentido em uma sociedade de consumo, em que o trabalho passa a servir de meio (para esse consumo) e em que as pessoas, além de produtoras, acabam tornando-se, elas mesmas, produtos a serem consumidos (e, consequentemente, descartados quando não mais tiverem utilidade). Entende-se que esta forma de organização social dificulta às pessoas um tempo para si mesmas, para a reflexão sobre os seus desejos, frustrações, necessidades e potencialidades (e isso, por vezes, também na situação da primeira escolha profissional). Desse modo, o tempo livre da aposentadoria acaba sendo visto como continuidade da vida laboral, na medida em que passa a ser configurado como um tempo - vazio - a ser ocupado. Nesse contexto, a possibilidade de escolha - quando existe - remete ao tipo de ocupação a ser exercida. 
Conclui-se que tal condição poderia ser diferente se se oportunizasse maior espaço para o movimento de interiorização, de questionamento constante das escolhas e reescolhas, ao longo da vida. Como bem observa Soares (2002):

a escolha não é dada como opção; não somos educados e estimulados a realmente escolher, ao contrário do que nos apregoa o capitalismo. O exercício da escolha, ou o exercício da consciência vem sendo diluído pela falta de oportunidades reais (p. 44).

Nesse sentido, entende-se que programas de orientação profissional para futuros aposentados só se justificam em uma sociedade como a nossa, pois, talvez, para a grande parte da população que precisa garantir a imediata inserção no mercado de trabalho, será apenas na aposentadoria que poderá, enfim, dar-se um tempo para pensar naquilo que deseja fazer. E, mesmo para aqueles profissionais que puderam escolher sua carreira de modo a vinculá-la a seus interesses e habilidades, poder-se-ia questionar em que medida o imperativo da organização do tempo pelo tempo do trabalho pôde ser incorporado sem tanto assujeitamento à supervalorização do trabalho, em detrimento de outras esferas da vida.

Por outro lado, não se pretende com isto anular os benefícios que orientações de tal monta podem trazer. E se, provavelmente, nossa sociedade ainda está longe de se organizar fora de uma lógica capitalista e se, como o discurso dos entrevistados mostrou, a pré-aposentadoria pode ser um momento privilegiado para o planejamento de novos projetos de vida, não há porque deixar de considerar a orientação profissional na preparação para a aposentadoria como uma oportunidade de refletir sobre as escolhas já feitas e de pensar em novas escolhas: seja a de uma nova carreira, de uma aposentadoria-lazer, de um retorno à família. Mas uma escolha consciente, uma decisão pessoal responsável.

Os discursos analisados insinuam possíveis temas a serem trabalhados em uma orientação, dentre eles: a relação identidade pessoal-identidade ocupacional; a organização do tempo pelo tempo de trabalho e as implicações disto para o uso do tempo livre; o sentimento de pertencimento a um grupo fora do contexto profissional; a questão financeira após a aposentadoria; a qualidade de vida. Além destes, temas apontados na literatura (Camarano, 2003; Duarte \& Santos, 2003; França, 2002; Felippe et al., 1999; Leal, 1991; Lucchiari, 1997; Soares et al., 2007), como a reinserção na família e a relação com os amigos, dúvidas quanto às leis e cálculo dos benefícios e a qualificação para uma eventual reinserção no mercado, embora não tenham sido abordados pelos entrevistados, também poderiam ser considerados.

Depreende-se do presente estudo que, mais do que se pensar em uma orientação para a aposentadoria, talvez fosse importante refletir sobre o lugar do trabalho na vida das pessoas e pensar em possibilidades de desenvolvimento da identidade pessoal em outros contextos que não apenas o do trabalho. E isso não apenas na fase que antecede à aposentadoria, mas ao longo de toda a vida. A Orientação Profissional pode dar uma importante contribuição nesse sentido, uma vez que possibilita, nos diferentes ciclos da vida, uma reflexão sobre a relação do indivíduo com o trabalho e com projetos futuros.

\section{Referências}

Amarilho, C. B. \& Carlos, S. A. (2006). O executivo-empreendedor, sua aposentadoria e o processo de afastamento do trabalho. Estudos sobre o envelhecimento, 8 (1), 61-88.

Bohoslavsky, R. (2003). Orientação profissional: a estratégia clínica. São Paulo: Martins Fontes.

Bruns, M. A. T. \& Abreu, A. S. (1997). O envelhecimento: encantos e desencantos da aposentadoria. Revista ABOP, 1 (1), 5-33. 
Calligaris, C. (2000). A adolescência. São Paulo: Publifolha.

Camarano, A. A. (2003). Mulher idosa: suporte familiar ou agente de mudança? Estudos Avançados, 17 (49), 35-63.

Chaui, M. (2000). Capítulo introdutório. In P. Lafargue, O direito à preguiça (pp. 9-56). São Paulo: Hucitec.

D'Andrea, F. F. (2000). Desenvolvimento da personalidade: enfoque psicodinâmico. Rio de Janeiro: Bertrand Brasil.

Duarte, C. V. \& Santos, M. A. (2003). “Já não posso fazer mais nada, posso?”: Descrições do mundo do trabalho e planos futuros em mulheres idosas institucionalizadas e residentes com familiares. In L. L. Melo-Silva \& M. A. Santos (Orgs.), Arquitetura de uma ocupação: orientação profissional teoria e prática (pp. 201-226). São Paulo: Vetor.

Dubar, C. (2005). A socialização: construção das identidades sociais e profissionais. São Paulo: Martins Fontes.

Felippe, L. R. H., Sandmann, H. M., Merthy, M. E., Fernandez, S. \& Bulgacov, Y. L. M. (1999). Programa de preparação para aposentadoria: uma política de desenvolvimento humano. InterAÇÃO, 3, 79-94.

França, L. H. (2002). Repensando a aposentadoria com qualidade: um manual para facilitadores de programas de educação para aposentadoria em comunidades. Rio de Janeiro: UERJ.

França, L. H. \& Stepansky, D. V. (2005). Educação permanente para trabalhadores idosos - o retorno à rede social. Boletim Técnico SENAC, Rio de Janeiro, 31(2), 46-55.

García, S. T., Guerra, C. T. \& Ardila, M. C. L. (2007). El anciano conformista un optimista con experiencia? Resonancias de una investigación sobre lo psicológico en la calidad de vida con personas mayores en Soacha y Sibaté. Universitas Psychologica, 6 (2), 263-268.

Grassi, M. V. F. C. (2007). Temporalidade e contemporaneidade. Pulsional Revista de Psicanálise, 20 (190), 46-55.

Guirado, M. (2006). Psicanálise e análise do discurso. São Paulo: EPU.

Guirado, M \& Lerner, R. (Orgs). (2007). Psicologia, pesquisa e clínica: por uma análise institucional do discurso. São Paulo: Annablume.

Haddad, E. G. (1986). A ideologia da velhice. São Paulo: Cortez.

Leal, M. G. S. (1991). Aposentadoria: questão psicológica? Revista do Departamento de Psicologia da UFF, 3, 27-32.

Lucchiari, D. H. S. (1997). A reorientação profissional: apoio em época de crise. Revista ABOP, 1 (1), 81-88.

Medrado, B. D. (1994). Caindo prá idade: a vivência da velhice em um contexto rural nordestino. Dissertação de mestrado, Curso de Psicologia, Universidade Federal de Pernambuco, Recife.

Morse, J. M. (1994). Designing founded qualitative research. In N. K. Denzin \& Y. S. Lincoln (Eds.), Handbook of qualitative research (pp. 220-235). California: Sage.

Mourão, L. \& Andrade, J. E. B. (2001). Significado do trabalho, caminhos percorridos e sinalização de tendências. In Anais do XXV ANPAD (p. 306). Salvador: Associação Nacional dos Programas de Pós-Graduação em Administração.

Oliveira, A. M. \& Santos, M. F. S. (2002). O envelhecer: teorias científicas x teorias populares. Psico, 33 (2), 311 326.

Rodrigues, M., Ayabe, N. H., Lunardelli, M. C. F. \& Canêo, L. C. (2005). A preparação para a aposentadoria: o papel do psicólogo frente a esta questão. Revista Brasileira de Orientação Profissional, 6 (1), 53-62.

Romanini, D. P., Xavier, A. A. P. \& Kovaleski, J. L. (2004). Aposentadoria: período de transformações e preparação. In Anais do XXIV ENEP (pp. 2469-2476). Florianópolis: Associação Brasileira de Engenharia da Produção.

Santos, M. F. S. (1990). Identidade e aposentadoria. São Paulo: EPU.

Sánchez, C. D. (2000). Gerontologia social. Buenos Aires: Espaço Editorial.

Silva, C. P., Goulart Junior, E., Ferreira, M. M. \& Garbulho, N. F. (2005). Uma experiência de preparação para a aposentadoria de funcionários públicos. In M. C. P. Lassance et al. (Orgs.), Intervenção e compromisso social - orientação profissional: teoria e técnica (pp. 425-440). São Paulo: VETOR.

Siqueira, R., Botelho, M. \& Coelho, F. (2002). A velhice: algumas considerações teóricas e conceituais. Revista Ciência e Saúde Coletiva, 7 (4), 899-906.

Soares, D. H. P.(2002). A escolha profissional do jovem ao adulto. São Paulo: Summus.

Soares, D. H. P. Costa, A. B., Rosa, A. M. \& Oliveira, M. L. S. (2007). Aposenta-ação: programa de preparação para aposentadoria. Estudos Interdisciplinares sobre o Envelhecimento, 12, 143-161. 
Stelmachuk, M. S. L. (2005). Sentidos do trabalho para idosos em exercício profissional remunerado. Dissertação de Mestrado, Programa de Pós-Graduação em Psicologia, Universidade Federal de Santa Catarina, Florianópolis.

Valore, L. A. (2005). Subjetividade no discurso de recém-graduados da UFPR: uma análise institucional. Tese de Doutorado, Instituto de Psicologia, Universidade de São Paulo, São Paulo.

Veloz, M. C. T., Nascimento-Schulzel, C. M. \& Camargo, B. V. (1999). Representações sociais do envelhecimento. Psicologia, Reflexão e Crítica, 12 (2), 479-501.

Zanelli, J. C. \& Silva, N. (1996). Programa de preparação para a aposentadoria. Florianópolis: Insular.

\section{Endereço para correspondência}

gabrielle@cuorecorpore.com.br, luvalore@uol.com.br
Recebido em: 01/10/2008

Aprovado em: 20/02/2009 